\title{
English Vocabulary Teaching Techniques at Junior Middle Schools
}

\author{
Xiaomei $\mathrm{Yu}^{1}$ \\ ${ }^{1}$ Guangdong University of Foreign Studies \\ Correspondence: Xiaomei Yu, Guangdong University of Foreign Studies, Baiyun District, Guangzhou, \\ Guangdong, China.
}

Received: September 27, 2020

Accepted: October 10, 2020

Online Published: October 14, 2020

doi: 10.5539/elt.v13n11p12

URL: https://doi.org/10.5539/elt.v13n11p12

\begin{abstract}
English teachers at junior middle schools often employ traditional vocabulary teaching techniques such as L1 equivalents, word lists, pictures, and word formation rules. They reinforce the students' retention of vocabulary by asking them to read aloud the words repeatedly and copy the new words as homework. In this study, suggestions are given to improve English vocabulary teaching techniques at junior middle schools.
\end{abstract}

Keywords: vocabulary, teaching techniques, Junior middle school

\section{Introduction}

Vocabulary is considered as the synonym of lexicon and lexis and defined as the stock of words in a given language (Jackson \& Amvela, 2000:1). It plays an essential role in oral communication since words are the components of human's speeches. However, foreign or second language teachers prefer teaching grammar while vocabulary is likely to be neglected. Maybe it is because grammar is a finite system, whereas vocabulary is not (Sheehan, 2004). And the traditional view is that beginner learners have to master the smallest amount of vocabulary when they begin to deal with the basic grammatical problems (O'Dell, 1997). In actual fact, without grammar very little can be conveyed; without vocabulary nothing can be conveyed (McCarten, 2007: 20). In ESL context, vocabulary supports the four macro language skills, and inadequacy of vocabulary knowledge is an obstacle to learning (Nam, 2010). It is suggested that more attention should be paid to vocabulary, and effective vocabulary teaching techniques deserve research so as to best help learners to acquire, store and retrieve words in the target language.

\section{A Review of Relevant Studies on English Vocabulary Teaching Techniques}

Classical vocabulary teaching techniques as well as some new methods have been studied in vocabulary researches (Nation \& Newton, 1997; Sökmen, 1997; Web, 2007; Balci \& Cakir, 2012). This study will review some of the techniques.

\subsection{Classical Vocabulary Teaching Techniques}

Between 1970s and 1980s, the emphasis was implicit and incidental learning of vocabulary. Students were taught to recognize clues in context, refer to monolingual dictionaries, and infer word meaning from context in textbooks. Implicit vocabulary instruction has its drawbacks. For example, guessing words in context is a slow process, and inferring word meaning may lead to errors (Sökmen, 1997). Webb's (2008) empirical study showed that context had little effect on gaining knowledge of form.

According to Nation \& Newton (1997), communication activities, role play for example, can encourage vocabulary learning. Group-based peer interaction can give the learners opportunities to encounter new items, and the activities will provide context for them to guess the meaning of the new items.

Teaching vocabulary through synonyms is also a classical technique. Erten \& Tekin (2008) claimed that this technique can cause confusion and take more time and effort than expected (Balci \& Cakir, 2012). But according to Webb's (2007) empirical study, learning words with known synonyms may be easier than learning words without known synonyms, because learners may be able to transfer their knowledge of syntax and collocation from known synonyms to less frequent synonyms, thus lightening the learning burden.

Other classical vocabulary teaching techniques include antonym, hyponym, definition, mother tongue translation, and so on (Balci \& Cakir, 2012). 


\subsection{New Vocabulary Teaching Techniques}

Some new vocabulary teaching techniques have been recommended, such as semantic mapping (brainstorming associations of a word and diagramming the results), ordering (arranging a list of words in a specific order), and pictorial schemata (creating grids or diagrams) Sökmen (1997). These techniques can help the students establish links between words.

Another technique which shows links between words is teaching vocabulary through collocations. In comparison with classical vocabulary teaching techniques, teaching through collocations can better facilitate learning and enhance retention of new vocabulary items (Balci \& Cakir, 2012). Learning collocations as chunks is more efficient than learning individual words (Sökmen, 1997).

\section{Current Trend of Vocabulary Teaching Techniques at Junior Middle Schools}

Junior middle school students are beginners of English who are more dependent on teachers' instruction than intermediate learners and advanced learners. Moreover, they tend to rely a lot on interest without which they may fail or even give up learning the language. Vocabulary teaching is gaining increasing attention due to the emphasis on vocabulary in examinations. For example, students are required to complete the word in a sentence with the help of the context and the first letter of the word. Considering the importance of vocabulary and the characteristics of the students, English teachers at junior middle school had better look for effective vocabulary teaching techniques.

To know about the common vocabulary teaching techniques, the author interviewed 16 English teachers from different junior middle schools by chatting on the internet. According to the preliminary survey, most of them employed traditional English vocabulary teaching techniques as follows:

1) Techniques of teaching pronunciation

Before a new lesson, the teacher asks the students to imitate him (her) or the tape recorder to pronounce the new words. We may call this process "listen-and-repeat". Students are taught to memorize the new words according to the pronunciation.

2) Techniques of teaching morphology

Rules of word formation are taught, such as compounding, derivation, conversion and blending. These methods can help the students identify the word class, and expand their vocabulary size.

3) Techniques of teaching meanings

Perhaps the most mechanical vocabulary teaching technique is using the word lists on the last few pages of the textbook. The equivalents provided are decontextualized and removed from communicative context. Usually only one of the meanings that occurs in the text is provided. Students may not be able to use the word in its other meanings.

Pictorial vocabulary teaching is a popular technique which is appropriate for students at the beginning levels. Teachers often show the corresponding picture of the target word through PPT instead of just providing an L1 equivalent. In this way, the meaning of the word is obvious to the students. More importantly, vivid pictures can arouse the students' interest and enhance their retention of the new word.

4) Techniques of teaching usage

According to Richards (1976), knowing a word means not only knowing its meaning but also its grammatical patterns (Sökmen, 1997). In this view, vocabulary teaching involves grammar. Teachers often teach the language points while or after teaching the passage where the new words occur. This technique is similar to teaching vocabulary through context.

In summary, English vocabulary teaching at junior middle schools tends to aim at examinations. Students are asked to read the word lists out of context, do drilling exercises, and copy the new words repeatedly as homework. Mechanical methods may be of little help for vocabulary learning.

\section{Recommended Techniques for English Vocabulary Teaching}

To select proper English vocabulary teaching techniques, teachers had better be clear about the English proficiency of the students as well as the goal of teaching. The best vocabulary teaching technique is one that is appropriate for the students and can reach the goal of teaching.

For beginner learners, repetition may be suitable, though it is considered as a shallow technique. Whereas teaching through synonyms may be more effective at a later stage than at an earlier stage of learning. In order to 
arouse the students' interest, vocabulary can be taught through pictures, songs, games, etc.

As for the goal of vocabulary teaching, the most direct orientation is to get the students to pass examinations. But it is more than simply covering a certain number of words on a word list (Jack, 1976). The ideal is that students not only know the pronunciation and spelling of a new word, but also know what other words it can co-occur with, how it should be used appropriately in different contexts, the way it is combined with other words in a sentence, how to create words based on morphological rules, how it is associated with others, and it semantic information (Sökmen, 1997). Of course, it is impossible and unrealistic to teach everything about a word at a time. Teachers can give priority to the special features of a particular word.

Nowadays, task-based teaching is popular in secondary schools. Students learn the language not only from input, but also from their output. Therefore, teachers can assign some vocabulary exercises to the students, such as gap-filling exercises, translating exercises, composition writing, and so on. Teachers can also design some class activities which can encourage language processing and promote a more in-depth understanding of the word, thus increasing the likelihood of students' long-term memory of the word. Different kinds of tasks may increase the exposures of a particular word to the student, which can also enhance the retention.

\section{Conclusions}

Nothing is perfect. Teachers should not stick to only one vocabulary teaching technique, but try employing different techniques according to the factors that affect the learning of words such as inflectional complexity, register restrictions, and multiplicity of meaning (Laufer, 1997). Moreover, teachers should choose teaching techniques based on the language proficiency of the students. Most importantly, teachers should teach ways to learn vocabulary so that the students can continue learning independently outside the classroom.

\section{References}

Balci, Ö., \& Cakir, A. (2012). Teaching vocabulary through collocations in EFL Classes: The case of Turkey. International Journal of Research Studies in Language Learning, 1(1), 21-32. https://doi.org/10.5861/ijrsll.2012.v1i1.31

Jack, C. R. (1976). The role of vocabulary teaching. TESOL Quarterly, 10(1), 77-89. https://doi.org/10.2307/3585941

Jackson, H., \& Amvela, E. Z. (2000). Words, Meaning and Vocabulary: An Introduction to Modern English Lexicology. The Cromwell Press, Trowbridge. https://doi.org/10.1086/493080

Laufer, B. (1997). What's in a word that makes it hard or easy: Some intralexical factors that affect the learning of words. In Schmitt, N., \& M. McCarthy (Eds.), Vocabulary: Description, Acquisition and Pedogogy (pp.140-155). Cambridge University Press.

McCarten, J. (2007). Teaching Vocabulary Lessons from the Corpus, Lessons for the Classroom. Cambridge University Press.

McCarthy. (Eds.). Vocabulary: Description, Acquisition and Pedogogy (pp. 237-258). Cambridge University Press.

Nam, J. (2010). Linking research and practice: Effective strategies for teaching vocabulary in the ESL classroom. TESL Canada Journal/Revue TESL Du Canada, 28(1), 127-135. https://doi.org/10.18806/tesl.v28i1.1064

Nation, I. S. P., \& Newton, J. (1997). Teaching vocabulary. In J. Coady, \& T. Huckin (Eds.), Second Language Vocabulary Acquisition (pp. 138-254). Cambridge University Press. https://doi.org/10.1017/CBO9781139524643.017

O’Dell, F. (1997). Incorporating vocabulary into the syllabus. In Schmitt, N., \& M. McCarthy (Eds.), Vocabulary: Description, Acquisition and Pedogogy (pp.258-278). Cambridge University Press.

Sheehan, A. (2004). Making sense of words. English Teaching Forum, 42(1), 1-11.

Sökmen, A. J. (1997). Current trends in teaching second language vocabulary. In Schmitt, N., \& M.

Webb, S. (2007). The effects of synonymy on second-language vocabulary learning. Reading in a Foreign Language, 19(2), 120-136.

Webb, S. (2008). The effects of context on incidental vocabulary learning. Reading in a Foreign Language, 20(2), 232-245.

\section{Copyrights}

Copyright for this article is retained by the author(s), with first publication rights granted to the journal.

This is an open-access article distributed under the terms and conditions of the Creative Commons Attribution license (http://creativecommons.org/licenses/by/4.0/). 